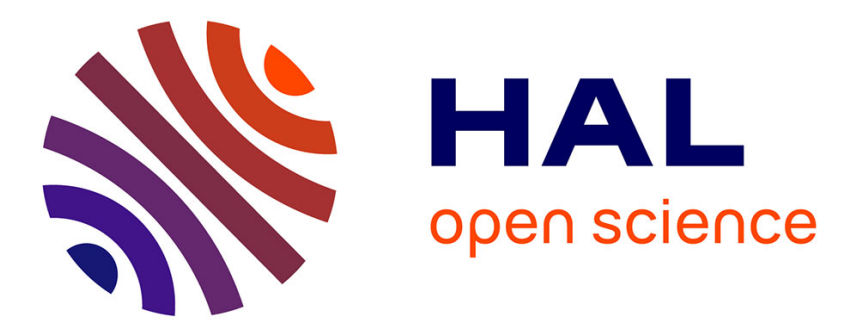

\title{
Randall's plaque as the origin of calcium oxalate kidney stones
}

\author{
Michel Daudon, Dominique Bazin, Letavernier Emmanuel
}

\section{To cite this version:}

Michel Daudon, Dominique Bazin, Letavernier Emmanuel. Randall's plaque as the origin of calcium oxalate kidney stones. Urolithiasis -Springer-, 2015, 43 (supplément 1), pp.5-11. 10.1007/s00240-0140703-y . hal-01148421

\section{HAL Id: hal-01148421 \\ https://hal.sorbonne-universite.fr/hal-01148421}

Submitted on 4 May 2015

HAL is a multi-disciplinary open access archive for the deposit and dissemination of scientific research documents, whether they are published or not. The documents may come from teaching and research institutions in France or abroad, or from public or private research centers.
L'archive ouverte pluridisciplinaire $\mathbf{H A L}$, est destinée au dépôt et à la diffusion de documents scientifiques de niveau recherche, publiés ou non, émanant des établissements d'enseignement et de recherche français ou étrangers, des laboratoires publics ou privés. 
Randall's plaque as the origin of calcium oxalate kidney stones

Michel Daudon ${ }^{1, *} \cdot$ Dominique Bazin $^{2} \cdot$ Emmanuel Letavernier $^{1}$

1 Laboratoire des Lithiases, Service des Explorations Fonctionnelles, Hôpital Tenon, APHP, 4, rue de la Chine, 75970 Paris Cedex 20, France, e-mail: michel.daudon@tnn.aphp.fr

2 Unité INSERM UMRS 1155, UPMC, Paris, France

3 CNRS, Laboratoire de Chimie de la Matière Condensée de Paris, UPMC, Collège de France, Paris, France

\begin{abstract}
Eight decades ago, Alexander Randall identified calcium phosphate deposits at the tip of renal papillae as the origin of renal calculi. The awareness that these "Randall's plaque" promote renal stone formation has been amplified during the past years by the development of endoscopic procedures allowing the in situ visualization of these plaques. Recent studies based upon kidney biopsies evidenced that apatite deposits at the origin of these plaque originate from the basement membranes of thin loops of Henle and then spread in the surrounding interstitium. In addition, scanning electron microscopy examination of calcium oxalate stones developed on Randall's plaque evidenced that plaque may also be made of tubules obstructed by calcium phosphate plugs. Hypercalciuria has been associated to Randall's plaque formation. However, several additional mechanisms may be involved resulting in increased tissular calcium phosphate supersaturation and the role of macromolecules in plaque formation remains elusive. At last, apatite crystals are the main mineral phase identified in plaques, but other calcium phosphates and various chemical species such as purines have been evidenced, revealing thereby that several mechanisms may be responsible for plaque formation.
\end{abstract}

Keywords Randall's plaque $\cdot$ Kidney stones $\cdot$ Calcium $\cdot$ Oxalate $\cdot$ Apatite

\title{
Introduction
}

Calcium oxalate $(\mathrm{CaOx})$ stones are now identified as the main type of urinary calculi in most countries throughout the world. They account for at least $70 \%$ of all stones developed in the upper urinary tract and even more in male patients [1]. In some parts of the world, $\mathrm{CaOx}$ was found as the main component of about $90 \%$ of all kidney stones [2]. Such a progression in $\mathrm{CaOx}$ stones accounts for the increase in the prevalence of kidney stone disease frequently reported during the past decades from countries where longitudinal epidemiological surveys are available as in the United States [3], in Europe [4, 5] or in Japan [6]. Among the risk factors involved in stone formation, low diuresis and imbalance in diet are well documented [7-9]. Although a lot of inherited or acquired diseases may induce kidney stone formation, all together account for less than 10-15\% of calcium stones in the general population. Thus, most of calcium stones result from biological disorders in urine such as hypercalciuria, hyperoxaluria and/or hypocitraturia without any "identified" pathology. Moreover, these disorders are inconstantly found when urine biochemistry is performed, suggesting the anomalies are intermittent or transient, or simply related to low diuresis, which results in an increased concentration of poorly soluble salts in urine. Thus, the so-called idiopathic nephrolithiasis is the bulk of calcium stones. However, during the last decade, a series of investigations by the group of Evan, Lingeman and Coe, highlighted the role of calcium phosphate deposits in the papilla tip as a starting point of $\mathrm{CaOx}$ stone formation [10-12]. Such deposits, termed Randall's plaque because they were first described by Alexander Randall in the 1930s, initiate in the basement membrane of the long Henle's loops and spread out in the interstitium around the Bellini's ducts close to the papillary epithelium. When the epithelium is disrupted, the calcium phosphate deposits are in contact with the supersaturated urine issued from the vicinal nephrons, thus favouring $\mathrm{CaOx}$ crystallization and trapping of the crystals at the surface of the plaque. Thereafter, the stone growth is driven by urine supersaturation.

\section{Original description of papillary calcified plaques by Randall}

More than 75 years ago, Alexander Randall reported a study on "The origin and growth of renal calculi", which appeared first in the New England Journal of Medicine [13] and the following year in the Annals of Surgery [14]. In this seminal paper, he described a hitherto unrecognized papillary lesion consisting in calcium phosphate deposits in the intertubular spaces of the renal papilla, observed in $19.6 \%$ of 1,154 pairs of kidneys examined at autopsy. He made three observations:

- first, this papillary lesion which appeared as a cream coloured area near the tip of the papilla was not on its surface, but was subepithelial in location; 
- second, the chemical composition of papillary plaques was shown to be made of calcium phosphate and carbonate;

- third, small calculi were found to be attached to plaque at the tip of papillae in 65 kidneys $(2.8 \%)$, their composition differing from that of the plaque. The stones were made of calcium oxalate;

- fourth, $\mathrm{CaOx}$ stones collected in routine practice often exhibited a portion which was smooth and somewhat depressed, resembling a facet corresponding with the morphology of the papilla.

Examining by light microscopy some calculi actually attached on a papillary plaque, Randall found that the stone was continuous with the interstitial plaque and that the epithelial covering of papilla was lost. Such aspect of calcium phosphate deposits in the interstitium was termed papillary lesion type 1 by Randall who proposed that papillary calcium deposits could act as a nidus for urinary salt accretion if epithelial covering of the papilla is lost. Randall also found in some cases Bellini's ducts filled by calcium phosphate plugs (termed papillary lesion type 2). He suggested the phosphate plugs may be another way for $\mathrm{CaOx}$ stone formation.
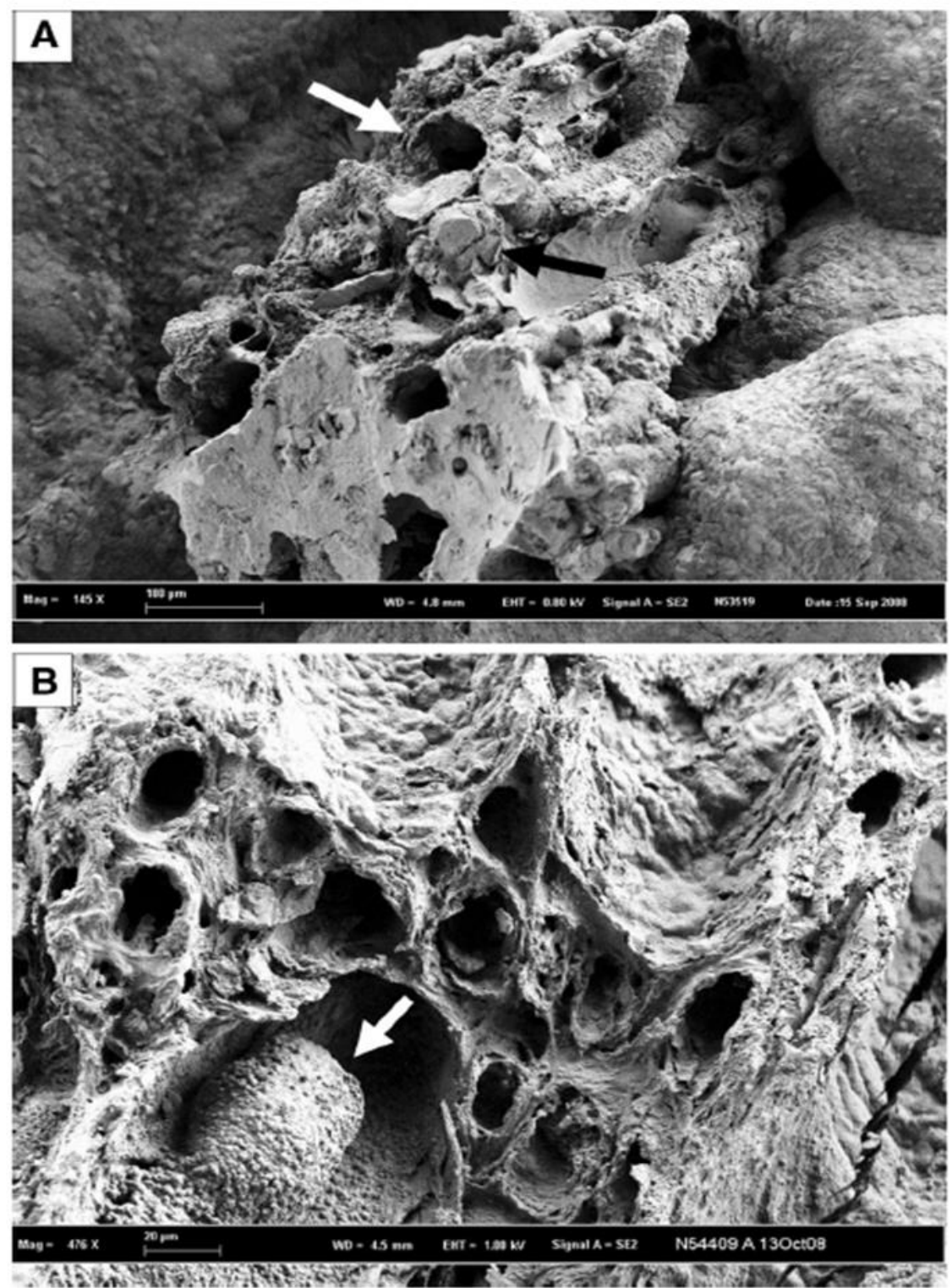

Fig. 1 Scanning electron microscopy photographs of calcium oxalate calculi initiated from a Randall's plaque. a The plaque is made of a mixing of tubules with calcified walls (white arrow) and of tubules obstructed by calcium phosphate plugs (black arrow). b Randall's plaque at the surface of another calcium oxalate stone with calcified tubules and a calcium phosphate plug partly obstructing the lumen of a collecting duct. 


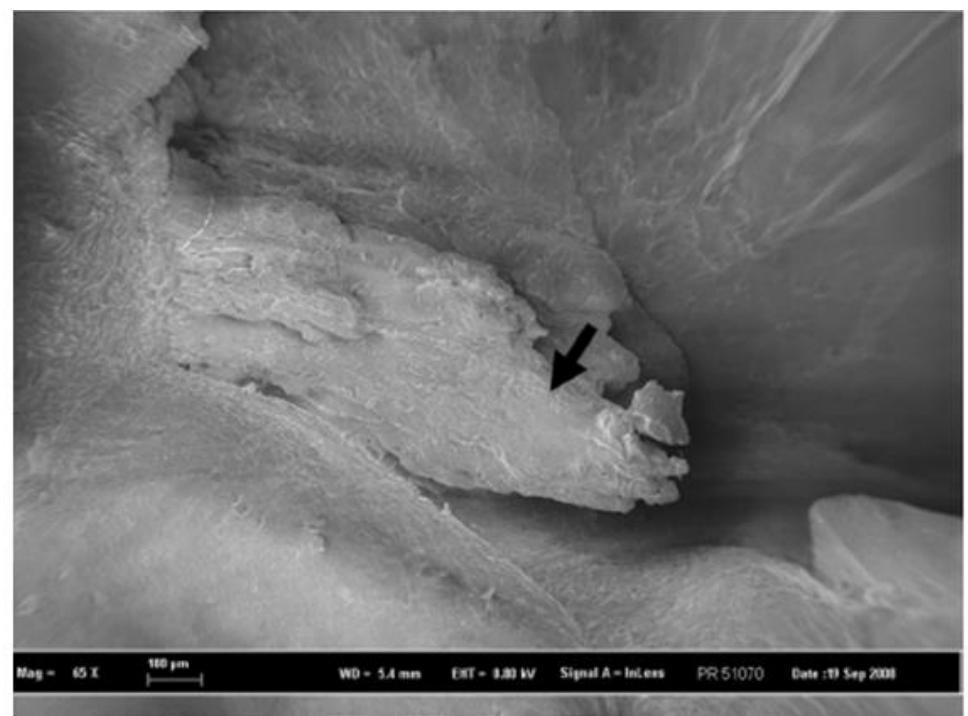

Fig. 2 Scanning electron microscopy photograph of a tubular plug (black arrow) at the origin of a calcium oxalate monohydrate stone

Scanning electron microscopy examination of $\mathrm{CaOx}$ stones developed from a Randall's plaque provides evidence that plaque is made of a mixing of tubules with calcified walls (white arrow, Fig. 1a) and of tubules obstructed by calcium phosphate plugs (black arrow, Fig. 1a or white arrow, Fig. 1b). Please note in Fig. 1b, the calcium phosphate cluster within the tubular lumen (white arrow), while other tubules are empty with calcified walls. In other cases, much less frequent, the nidus of the stone appears only as a tubular plug (Fig. 2, black arrow). At the time Randall performed his studies, he could not identify the exact location and nature of calcium deposits within the papillary structure. Nor, due to the forensic nature of his study material, could he evaluate urinary solute excretion in the affected individuals.

\section{Epidemiological considerations}

Other authors confirmed the findings of Randall in autopsy studies during the same period: for example, Rosenow found plaques in $22.2 \%$ of 239 kidneys, whereas Anderson observed plaques in $12 \%$ of kidneys in a series of 1,500 necropsies [15, 16]. In South Africa, Vermooten [17] examined 1,060 pairs of kidneys. He found Randall's plaques in $17.2 \%$ of Caucasians and only $4.3 \%$ of Bantus, a finding in keeping with his observation of the lower incidence of calcium nephrolithiasis in the local population of African descent than Caucasian descent. Papillary calcifications were seen in the subepithelial interstitial tissue together with collagen fibres, and were not found in the lumen of collecting ducts [18]. Forty years after the first description of papillary calcified deposits acting as a nidus for calcium stone formation, Luis Cifuentes-Delatte, a Spanish urologist enthusiastic for research on stone formation observed with his colleagues that 142 out of 500 consecutive calculi exhibited a concavity characteristic of a papillary origin [19]. In 61 (43\%) of these umbilicated calculi, plaques were typically made of apatite, some of them showing calcified collecting ducts [20].

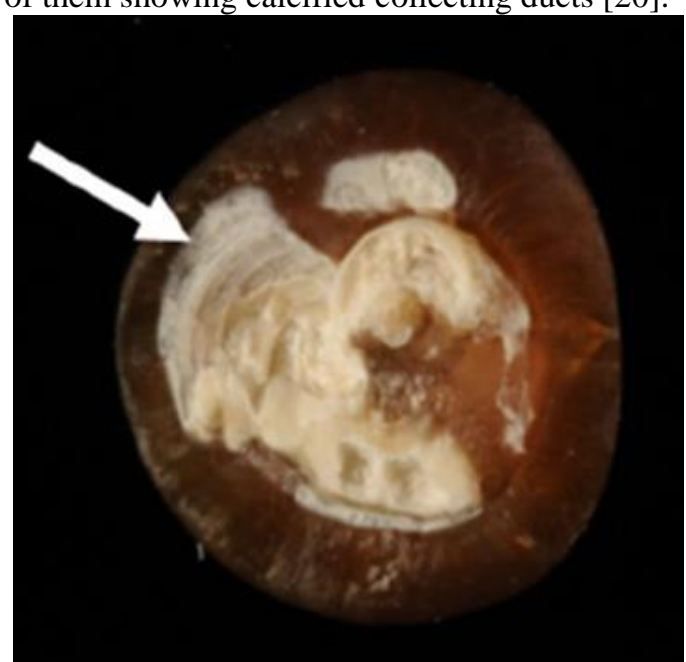

Fig. 3 Whewellite stone initiated from a carbapatite Randall's plaque (white arrow) 


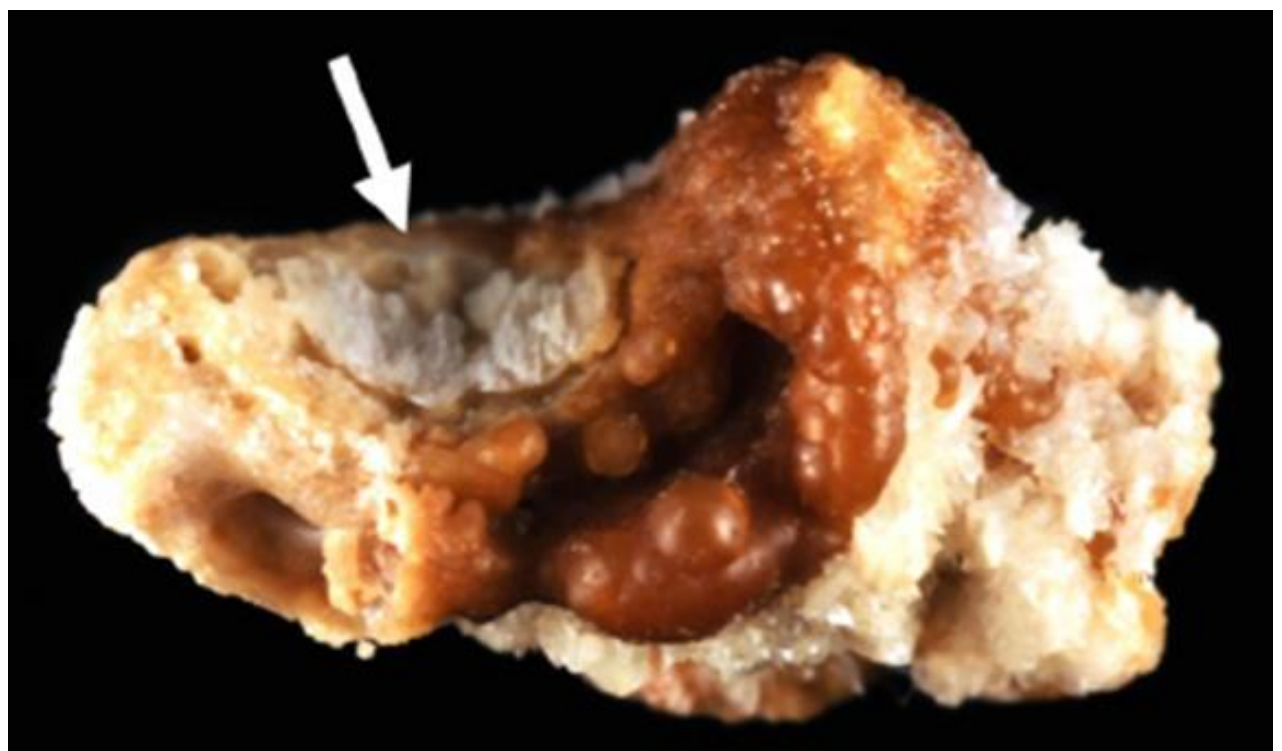

Fig. 4 Mixed stone made of whewellite and weddellite nucleated from a Randall's plaque (white arrow)

In our experience, based upon 45,774 calculi referred to the Necker hospital stone laboratory over the past three decades, we found by morphologic examination coupled with FTIR analysis that 8,916 (19.5\%) calculi exhibited a depressed surface (umbilication) suggestive of a papillary attachment [21]. Most of these stones (92.5 $\%$ ) were made of $\mathrm{CaOx}$ monohydrate (whewellite) either pure (Fig. 3) or admixed with $\mathrm{CaOx}$ dihydrate (weddellite) as observed in Fig. 4. As previously reported, the composition of Randall's plaque is carbapatite in $90 \%$ of cases, but other crystalline phases may be found as main component of Randall's plaque such as amorphous calcium phosphate, brushite or whitlockite, or trioxypurines like sodium urate [19, 21].

However, detailed endoscopic examination of renal cavities during percutaneous nephrolithotomy (PNL) or ureteroscopic procedures suggests a much higher prevalence of Randall's plaques than that deduced from stone examination. An explanation could be that modern urological treatment to remove stones often use fragmentation techniques such as shockwaves, ultrasounds or laser. As a consequence, stone fragments collected for analysis may have lost both the part of Randall's plaque fixed to the stone and the typical depressed face. In 1997, using endoscopic procedures, Low and Stoller reported the presence of Randall's plaques on one or more papillae in $74 \%$ of 57 stone formers, the prevalence being $88 \%$ for $\mathrm{CaOx}$ stones [22]. In 2006, Matlaga et al. [23] found that $91 \%$ of papillae in 23 patients with idiopathic $\mathrm{CaOx}$ nephrolithiasis harboured plaques and half of papillae had attached calculi. Digital imaging provided undisputable evidence of stone attachment to plaque. Indeed, epidemiological differences in the occurrence of Randall's plaques may be observed according to the investigated population. Recent reports from European countries suggest that Randall's plaque could be less frequent in Europe than in the United States. In Italy, Ruggera et al. reported the occurrence of Randall's plaque in $44.4 \%$ of 27 stone formers who underwent ureterorenoscopy or PNL and renal papillae biopsy [24]. In France, Olivier Traxer found Randall's plaques in $57 \%$ of 287 stone formers who underwent flexible ureterorenoscopy. They were observed on all papillae in $54 \%$ of these patients. Such plaques were visible in only $27 \%$ of 173 non-stone forming patients $[25,26]$. 


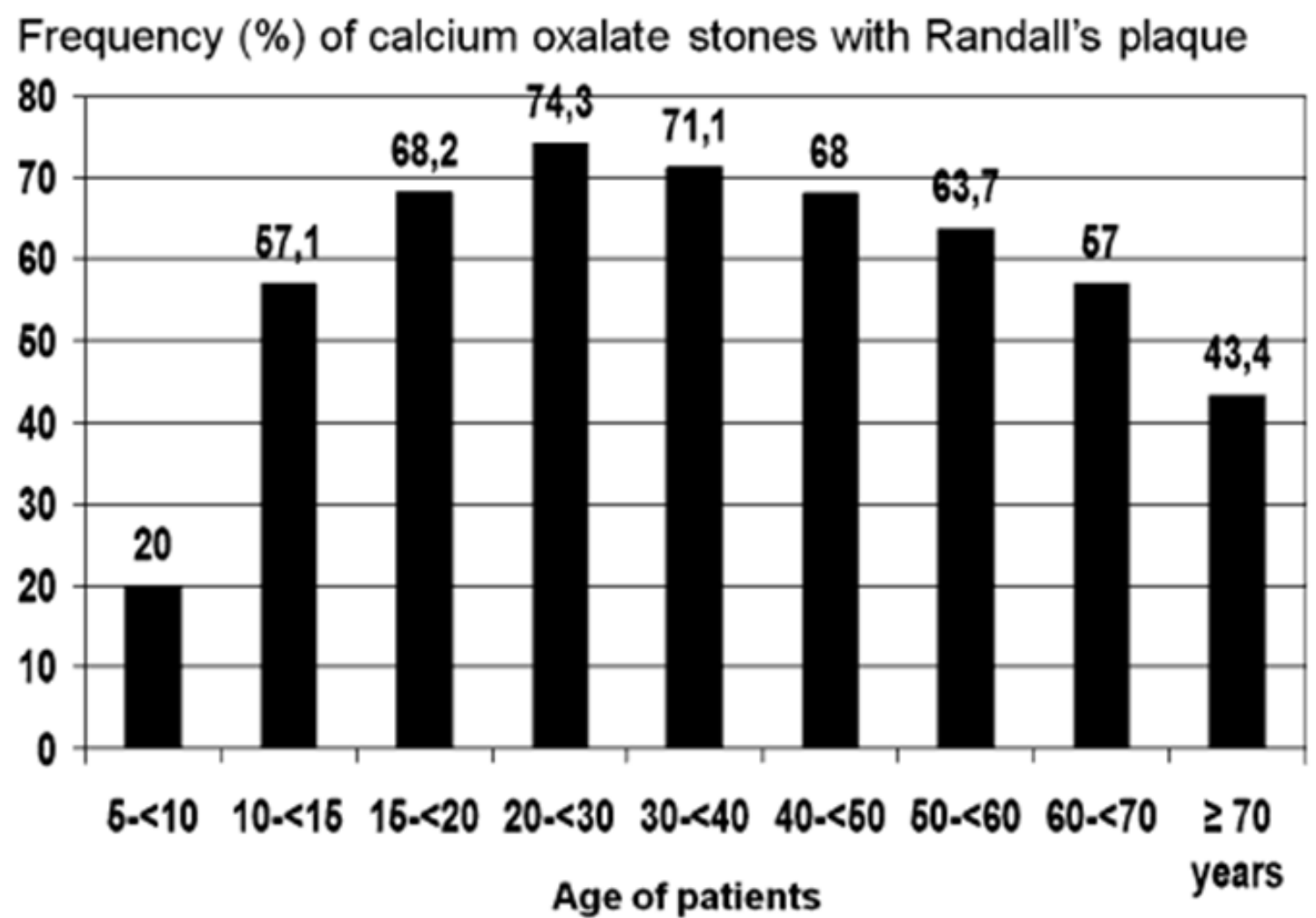

Fig. 5 Occurrence (\%) of Randall's plaque at the origin of spontaneously passed calcium oxalate stones according to the patient's age

Of note, in France, stones harbouring an umbilication were found to be three times more frequent in the recent years than at the beginning of the 1980s and patients were younger and younger [27]. Children may form $\mathrm{CaOx}$ stones from Randall's plaque. As shown in Fig. 5, when considering only unfragmented stones spontaneously passed or removed by urological procedures without fragmentation, the part of stones developed from a Randall's plaque is very high and dramatically increasing with age from childhood up to the age class 2030 years, then slowly decreasing thereafter. In our experience, $39 \%$ of all spontaneously passed stones had a typical umbilication on their surface and 5,728 among 8,662 (66.1\%) of spontaneously passed $\mathrm{CaOx}$ monohydrate calculi were umbilicated and were developed from a Randall's plaque.

\section{Randall's plaques begin in basement membranes of thin Henle's loops}

In an elegant study, Evan and co-workers recently provided substantial advances in the pathogenesis and structure of Randall's plaques in patients with $\mathrm{CaOx}$ stones [10]. They took superficial biopsy specimens from papillae in the upper, middle and lower poles of a kidney during PNL performed for stone removal in 15 patients with recurrent, idiopathic $\mathrm{CaOx}$ nephrolithiasis, all of whom were hypercalciuric, and in 4 patients with $\mathrm{CaOx}$ stones and hyperoxaluria due to jejuno-ileal bypass for obesity.

By light microscopy, they confirmed Randall's plaques to be in subepithelial position at the papillary tip, surrounding the openings of the ducts of Bellini. Calcium-containing deposits were found surrounding primarily the thin loops of Henle. Electron microscopy revealed these deposits to be located within the basement membrane of Henle's loops and around adjacent vasa recta, but not within the cytoplasm of the cells. Infrared microspectroscopy of deposits identified spectral bands characteristics of hydroxyapatite, associated with calcium carbonate in about $20 \%$ of cases. In summary, papillary plaques are interstitial and composed of apatite, originate in the basement membrane of the thin loops of Henle and subsequently spread into the surrounding interstitium, in the vasa recta and in the basement membranes of collecting ducts, without affecting collecting duct cells themselves. As said by the authors, "the overall impression is that the basement membrane of thin limbs is indeed the origin of plaque".

In contrast, none of the four patients with enteric hyperoxaluria due to jejuno-ileal bypass exhibited such papillary plaques. Instead, they exhibited intratubular hydroxyapatite crystals in the lumen of some collecting ducts, attached to their apical surface. Thus, the site of initial crystallization differed according to the underlying metabolic abnormality. Of note, four non-stone-formers subjected to nephrectomy, taken as controls, had neither papillary plaques nor tubular crystals [10]. Looking for risk factors associated with Randall's plaque formation, 
Kuo et al. found that low urine output, high calcium content and low urine $\mathrm{pH}$ were significantly more frequent in calcium stone formers with than without Randall's plaque [28]. Moreover, Kim and coworkers reported that stone episodes were proportional to the coverage of papilla by Randall's plaques [29].

\section{Role of hypercalciuria in the pathogenesis of Randall's plaques}

Evan and co-workers speculate that hypercalciuria should be the main explanation at the origin of Randall's plaques [10]. Before examining their arguments, one may remember that an epidemiologic case/control study identified high urinary calcium concentration to be the major risk factor for idiopathic calcium nephrolithiasis [30], whereas oxalate, uric acid and citrate concentrations did not differ between incident stone formers and contemporary controls. In the study of Evan et al. [10], the mean calcium excretion was $312 \mathrm{mg} / \mathrm{day}$ (7.8 $\mathrm{mmol} /$ day) in the $15 \mathrm{CaOx}$ stone Fig. 5 Occurrence (\%) of Randall's plaque at the origin of spontaneously passed calcium oxalate stones according to the patient's age formers, compared to $113 \mathrm{mg} / \mathrm{day}(2.8 \mathrm{mmol} / \mathrm{day}, \mathrm{p}$ $<0.01)$ in the 4 non-lithiasic controls.

According to the authors and to the editorial comments of their work by Bushinsky [31], the sequence of events could be as follows. Hypercalciuria is associated with intestinal calcium absorption, which results in postprandial peaks in serum calcium, reflected in increased calcium concentration in glomerular filtrate and in the fluid presented to the thin limbs, then to the thick ascending limb. High calcium reabsorption at this site enriches the outer medulla with calcium, which is washed into the deep medulla by the descending vasa recta.

The origin of calcium phosphate deposits in the interstitium may be the consequence of several mechanisms. As reported by Asplin and co-workers [32], the narrow part of the long loops of Henle is often supersaturated for calcium phosphate, which may precipitate. Despite the short transit time in that part of the nephron (20-30 s), where most particles remain free in the tubular lumen, some of them may be attached to the apical cell membrane, especially if urinary macromolecules and other inhibitors such as citrate are in low concentration or if an oxidative stress was able to damage the cell surface. Then, an endocytosis process may be initiated to eliminate them by intracellular dissolution [33]. Calcium and phosphate ions resulting from the

apatite dissolution are transferred in the interstitium and may locally induce high $\mathrm{CaP}$ supersaturation favouring new crystallization of apatite in the basement membrane of thin limbs, which is unusually thick and is composed of collagen with abundant mucopolysaccharides. Apatite crystals, once initiated, are able to accumulate and extend in the interstitium. At the microscopic scale, Evan et al. have shown that apatite crystals are composed of successive layers of mineral and macromolecules such as osteopontin [11]. Extensive accumulation of interstitial calcium deposits up to the papillary epithelium may result in a disruption of the epithelium by a yet poorly understood mechanism, thus making the apatite crystals exposed to the supersaturated urine. In the first following steps, new layers of calcium phosphate and macromolecules may cover the plaque, after what $\mathrm{CaOx}$ crystals formed in the surrounding supersaturated urine may be attached on the plaque, thus initiating stone formation $[11,26]$.

As underlined by Tiselius [34], calcium phosphate precipitation requires high CaP supersaturation, which is favoured by high $\mathrm{pH}$ value, high concentration of calcium and/or phosphate ions. Indeed, the physicochemical environment in the interstitium of the inner medulla favours calcium phosphate supersaturation around the tip of Henle's loops, especially in the presence of hypercalciuria and low urine output. In case of an excessive acid load, as observed in patients who eat large amounts of animal proteins, an increased excretion of $\mathrm{H}+$ ions by the collecting duct cells results in a low urine $\mathrm{pH}$ and an increased production of bicarbonate ions transferred to the interstitium. High protein intake is also responsible for a high excretion of phosphate ions, which could be another favouring factor for explaining calcium phosphate supersaturation in tubular lumen and the papillary interstitium.

As a result of the high acid load (the same is observed in the case of antidiuresis), the $\mathrm{pH}$ increases in the inner medulla, inducing supersaturation of calcium phosphate that may precipitate. Moreover, in hypercalciuric states, which appear to be more frequent in patients with Randall's plaques, a default of calcium reabsorption in the proximal part of the tubule results in an increased delivery of calcium in the distal part of the nephron, which may contribute to the supersaturation of calcium phosphate and/or $\mathrm{CaOx}$ [35]. In the case of low diuresis, the hyaluronic acid content in the inner medulla decreases [36] thus reducing its availability to act as an inhibitor of crystallization and results in increased concentration of solutes in the interstitium. 


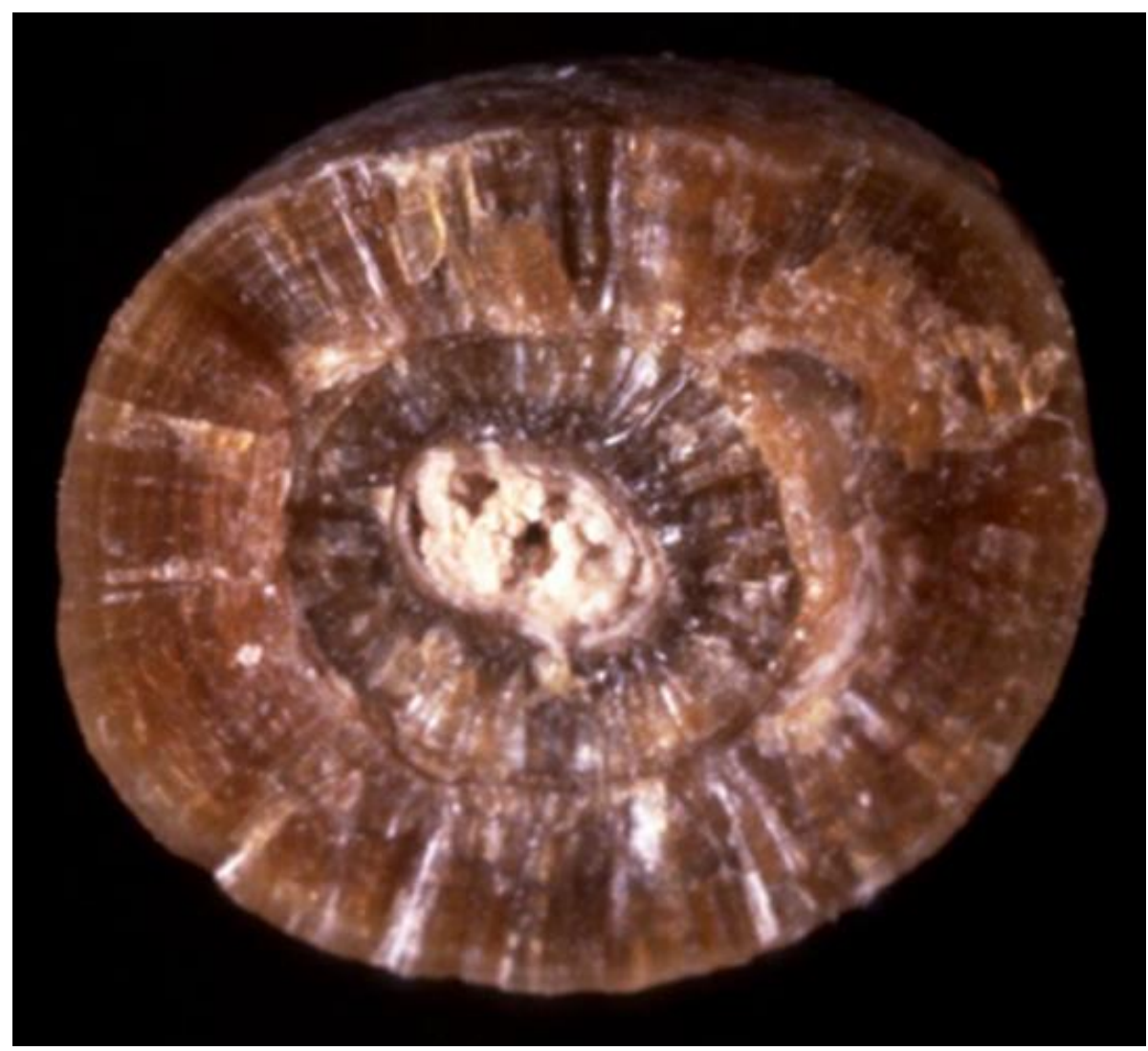

Fig. 6 Section of a whewellite stone exhibiting a whitish core made of carbapatite containing holes highly suggestive of Randall's plaque with calcified tubules

While endocytosis of $\mathrm{CaP}$ particles or secondary precipitation of $\mathrm{CaP}$ in the basement membrane of the cells may result from local high supersaturation, another phenomenon could explain why $\mathrm{CaOx}$ crystals may be secondary deposited on the CaP Randall's plaque after the papillary epithelium has been lost by a yet unexplained mechanism. Indeed, it is well known that CaP particles are the most frequent mineral phases found in urine [37]. In the case of low diuresis or high acid load, the secretion of $\mathrm{H}+$ in the distal part of the nephron results in a rapid decrease of the $\mathrm{pH}$ inducing dissolution of $\mathrm{CaP}$ particles. As a consequence, an increased calcium concentration may increase enough the $\mathrm{CaOx}$ supersaturation to induce nucleation of $\mathrm{CaOx}$ crystals that are excreted in the caliceal cavities $[3,38]$ and then may be fixed on the CaP particles at the surface of the papilla [26]. Then, the stone growth depends on the level of $\mathrm{CaOx}$ supersaturation, which is linked to the diuresis, and the concentration of both calcium and oxalate, and also of inhibitors such as citrate. When the stone is too large or too heavy for the mechanical resistance of the Randall's plaque that plaque may be disrupted and the stone free in the caliceal space. Thereafter, it may be rapidly spontaneously passed (the most frequent situation) or retained in the calyx. In such case, new $\mathrm{CaOx}$ crystals may progressively cover the umbilication and the calcium phosphate plaque, which disappears at the surface of the stone. When removed or spontaneously expelled, the stone does not exhibit any Randall's plaque which is found in the core of the stone as suggested by Miller et al. [39] and illustrated in Fig. 6.

\section{Randall's plaque and stone composition}

First studies by Evan and co-workers suggest that apatite crystals are the mineral phase for interstitial plaque and that amorphous calcium phosphate (ACP) deposits may cover the plaque secondly after it outcrops at the surface of the epithelium [11]. However, as suggested by Tiselius [34] ACP formation is favoured by high $\mathrm{CaP}$ supersaturation, which may occur not only in the urine, but also in the interstitium. In fact, other works suggest that ACP may be more abundant in the interstitial part of the Randall's plaque than at its surface [40]. As previously reported, Randall's plaque is made of carbapatite in most cases, but other calcium phosphates and other chemical species, such as sodium urate may be identified within Randall's plaque [21]. As shown in Table 1 , about 15 different crystalline species were found among 11,016 calculi exhibiting a papillary umbilication. Carbapatite was identified in $97.6 \%$ of cases, either pure or mixed with other calcium phosphates or other compounds such as purines. However, in some cases, carbapatite was not detected and then, another mechanism 
than Randall's plaque may be involved in stone formation. We cannot exclude that some of these compounds such as uric acid were only deposited at the surface of the papilla because of a local tissue lesion and then acted as a factor for heterogeneous nucleation of calcium oxalate. Of note, around the Randall's plaque the first layers of the stone are made in most cases by $\mathrm{CaOx}$ monohydrate $[21,38]$.

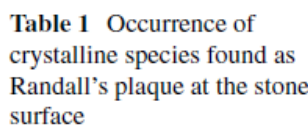

\begin{tabular}{lccc}
\hline Components of papillary deposits & Main & Minor & Total occurrence \\
\hline Calcium phosphates & $10716(97.3)$ & - & $10894(98.9)$ \\
Carbapatite & $10404(94.4)$ & $351(3.2)$ & $10755(97.6)$ \\
Amorphous carbonated calcium phosphate & $264(2.4)$ & $629(5.7)$ & $893(8.1)$ \\
Whitlockite & $30(0.3)$ & $87(0.8)$ & $117(1.0)$ \\
Octacalcium phosphate & $3(0.03)$ & $13(0.12)$ & $16(0.15)$ \\
Brushite & $15(0.14)$ & $23(0.2)$ & $38(0.34)$ \\
Other species & $300(2.7)$ & - & $503(4.6)$ \\
Struvite & $3(0.03)$ & $9(0.08)$ & $12(0.1)$ \\
Bobierrite & $2(0.02)$ & 0 & $2(0.02)$ \\
Calcite & $9(0.08)$ & $12(0.1)$ & $21(0.2)$ \\
Sodium hydrogen urate & $232(2.1)$ & $138(1.25)$ & $370(3.4)$ \\
Uric acid & $43(0.4)$ & $24(0.2)$ & $67(0.6)$ \\
Ammonium urate & $4(0.04)$ & $3(0.03)$ & $7(0.06)$ \\
Potassium urate & $4(0.04)$ & 0 & $4(0.04)$ \\
Opaline silica & $2(0.02)$ & $1(0.01)$ & $3(0.03)$ \\
Porphyrines & $1(0.01$ & $16(0.15)$ & $17(0.15)$ \\
Total number of samples & $11016(100)$ & $1291(11.7)$ & - \\
\hline
\end{tabular}

\section{Conclusion}

Idiopathic $\mathrm{CaOx}$ stones, the occurrence of which has been frequently reported as increasing during the past half century, mainly from a Randall's plaque made of carbapatite. In parallel, the progress in endoscopic material and optics, making easy the visual inspection of kidney papillae provides evidence that Randall's plaques are become very common in stone formers as in the general population. Such changes are in line with indepth modifications in dietary habits in industrialized countries over the past decades. A better knowledge regarding the mechanisms involved in the formation of calcified deposits within the inner medulla of the kidney is required in order to provide efficient advices able to reduce the occurrence of Randall's plaque and stone formation.

\section{References}

1. Curhan GC (2007) Epidemiology of stone disease. Urol. Clin. North Am 34:287-293

2. Ansari MS, Gupta NP, Hemal AK, Dogra PN, Seth A, Aron M, Singh TP (2005) Spectrum of stone composition: structural analysis of 1050 upper urinary tract calculi from northern India. Int J

Urol 12(1):12-16

3. Denstedt JD, Fuller A (2012) Epidemiology of stone disease in North America. In: Talati JJ, Tiselius HG, Albala DM, Ye Z (eds) Urolithiasis: basic science and clinical practice. Springer, London, pp 13-20

4. Hesse A, Brandle E, Wilbert D, Kohrmann KU, Alken P (2003) Study on the prevalence and incidence of urolithiasis in Germany comparing the years 1979 vs. 2000. Eur Urol 44:709-713

5. T rinchieri A (2006) Epidemiological trends in urolithiasis: impact on our health care systems. Urol Res 34:151-156

6. Ogawa Y (2012) Epidemiology of stone disease over a 40-year period in Japan. In: Talati JJ, Tiselius HG, Albala DM, Ye Z (eds) Urolithiasis: basic science and clinical practice. Springer, London, pp 89-96

7. Siener R (2006) Impact of dietary habits on stone incidence. Urol Res 34:131-133

8. Asselman M, Verkoelen CF (2008) Fructose intake as a risk factor for kidney stone disease. Kidney Int 73:139-140

9. T aylor EN, Fung TT, Curhan GC (2009) DASH-style diet associates with reduced risk for kidney stones. J Am Soc Nephrol 20:2253-2259

10. E van AP, Lingeman JE, Coe FL et al (2003) Randall's plaque of patients with nephrolithiasis begins in basement membranes of thin loop of Henle. J Clin Invest 111:607-616 
11. E van AP, Coe FL, Lingeman JE et al (2007) Mechanism of formation of human calcium oxalate renal stones on Randall's plaque. Anat Rec (Hoboken) 290:1315-1323

12. E van AP, Lingeman JE, Worcester EM, et al. Contrasting histopathology and crystal deposits in kidneys of idiopathic stone formers who produce hydroxy apatite, brushite, or calcium oxalate stones. Anat Rec (Hoboken). 2014 Jan 30. doi:10.1002/ar.22881. [Epub ahead of print] 13. Randall A (1936) An hypothesis for the origin of renal calculus. N Engl J Med 214:234-237

14. Randall A (1937) The origin and growth of renal calculi. Ann Surg 105:1009-1027

15. Rosenow EC Jr (1940) Renal calculi: study of papillary calcification. J Urol 44:19-28

16. Anderson WAD (1940) Renal calcification in adults. J Urol 44:29-34

17. V ermooten V (1941) The incidence and significance of the deposition of calcium plaques in the renal papilla as observed in the Caucasian and Bantu population in South Africa. J Urol

46:193-196

18. V ermooten V (1942) Origin and development in renal papilla of Randall's calcium plaques. J Urol 48:27-37

19. Cifuentes-Delatte L, Minon-Cifuentes J, Medina JA (1987) New studies on papillary calculi. J Urol 137:1024-1029

20. Cifuentes-Delatte L, Minon-Cifuentes JL, Medina JA (1985) Papillary stones: calcified renal tubules in Randall's plaques. J Urol 133:490-494

21. Daudon M, Traxer O, Jungers P, Bazin D. Stone morphology suggestive of Randall's plaque. In: Evan AP, Lingeman JE, Williams JC Jr (eds): Renal stone disease. American Institute of Physics

Conference Proceedings, Melville, New York, 2007, vol 900, pp. 2634

22. Low RK, Stoller ML (1997) Endoscopic mapping of renal papillae for Randall's plaques in patients with urinary stone disease. J Urol 158:2062-2064

23. Matlaga BR, Williams JC Jr, Kim SC et al (2006) Endoscopic evidence of calculus attachment to Randall's plaque. J Urol 175:1720-1724

24. Ruggera L, Chiodini S, Gambaro G, et al. (2008) Does Randall's plaque represent a necessary condition in the pathogenesis of the idiopathic calcium oxalate stones? In: Abstracts of the 11th international symposium on urolithiasi, Nice, 2-5 September 2008. Urol Res, vol 36, pp 162-163 (A)

25. Carpentier X, Daudon M, Bazin D, Traxer O (2009) Plaques de Randall: fréquence, topographie et classification. Sémin Urol Néphrol 35:86-90

26. Daudon M, Traxer O, Williams JC, Bazin DC (2011) Randall's plaques. In: Rao PN, Preminger GM, Kavanagh JP (eds) Urinary tract stone disease. Springer, London, pp 103-112

27. Daudon M (2005) Épidémiologie actuelle de la lithiase rénale en France. Ann Urol 39:209-231

28. Kuo RL, Lingeman JE, Evan AP et al (2003) Urine calcium and volume predict coverage of renal papilla by Randall's plaque. Kidney Int 64:2150-2154

29. Kim SC, Coe FL, Tinmouth WW et al (2005) Stone formation is proportional to papillary surface coverage by Randall's plaque. J Urol 173:117-119

30. Curhan GC, Willett WC, Speizer FE, Stampfer MJ (2001) Twenty-four-hour urine chemistries and the risk of kidney stones among women and men. Kidney Int 59:2290-2298

31. Bushinsky DA (2003) Nephrolithiasis: site of the initial solid phase. J Clin Invest 111:602-605

32. Asplin JR, Mandel NS, Coe FL (1996) Evidence of calcium phosphate supersaturation in the loop of Henle. Am J Physiol 270:F604-F613

33. Lieske JC, Norris R, Swift H, Toback FG (1997) Adhesion, internalization and metabolism of calcium oxalate monohydrate crystals by renal epithelial cells. Kidney Int 52:1291-1301

34. T iselius HG (2013) The role of calcium phosphate in the development of Randall's plaques. Urolithiasis 41:369-377

35. W orcester EM, Coe FL, Evan AP et al (2008) Evidence for increased postprandial distal nephron calcium delivery in hypercalciuric stone forming patients. Am J Physiol Renal Physiol

295:F1286-F1294

36. Hansell P, Goransson V, Odlind C, Gerdin B, Hallgren R (2000) Hyaluronan content in the kidney in different states of body hydration. Kidney Int 58:2061-2068

37. Smith LH, Werness PG (1983) Hydroxyapatite-the forgotten crystal in calcium urolithiasis. Trans Am Clin Chem Assoc 95:183-190

38. Sethmann I, Grohe B, Kleebe HJ (2014) Replacement of hydroxylapatite by whewellite: implications for kidney-stone formation. Mineral Mag 78:91-100 
39. Miller NL, Williams JC Jr, Evan AP et al (2010) In idiopathic calcium oxalate stone-formers, unattached stones show evidence of having originated as attached stones on Randall's plaque. BJU Int 105:242-245

40. Carpentier X, Bazin D, Jungers P, Reguer S, Thiaudière D, Daudon M (2010) The pathogenesis of Randall's plaque: a papilla cartography of Ca compounds through an ex vivo investigation based on XANES spectroscopy. J Synchrotron Radiat 17:374-379 